\title{
Anti-PAD4 autoantibodies in rheumatoid arthritis: levels in serum over time and impact on PAD4 activity as measured with a small synthetic substrate
}

\author{
Sylvie Pollmann • Maria Stensland • Eirik Hornes Halvorsen • Ludvig M. Sollid • \\ Tore K. Kvien · Burkhard Fleckenstein • Øyvind Molberg
}

Received: 20 August 2010/Accepted: 30 December 2010/Published online: 26 January 2011

(C) The Author(s) 2011. This article is published with open access at Springerlink.com

\begin{abstract}
Isoform 4 of the human peptidylarginine deiminase (hPAD4) enzyme may be responsible for the citrullination of antigens in rheumatoid arthritis (RA) and has been shown to be itself the target of disease-specific autoantibodies. Here, we have tested whether the level of serum anti-hPAD4 antibodies in RA patients is stable over a period of 10 years and whether the antibodies influence hPAD4-mediated deimination of the small substrate $N$ - $\alpha$ Benzoyl-L-arginine ethyl ester. RA sera $(n=128)$ obtained at baseline and after 10 years were assessed for antihPAD4 antibodies by a specific immunoassay. For 118 RA patients, serum anti-hPAD4 IgG levels were stable over 10 years. Seven patients who were negative for anti-PAD4 IgG at baseline had become positive after 10 years. Further, total IgG from selected RA patients and controls were purified, and a fraction was depleted for anti-hPAD4 antibodies. Kinetic deimination assays were performed with total IgG and depleted fractions. The $k_{c a t}$ and $K_{m}$ values of hPAD4-mediated deimination of $N$ - $\alpha$-Benzoyl-L-arginine ethyl ester were not affected by the depletion of the antihPAD4 antibodies from the total IgG pool. In conclusion, RA patients remain positive for anti-hPAD4 antibodies
\end{abstract}

S. Pollmann · M. Stensland · E. H. Halvorsen ·

L. M. Sollid · B. Fleckenstein · Ø. Molberg (凹)

Centre for Immune Regulation, Institute of Immunology,

University of Oslo, Oslo University Hospital-Rikshospitalet, 0027 Oslo, Norway

e-mail: oyvind.molberg@medisin.uio.no

T. K. Kvien

Department of Rheumatology,

Diakonhjemmet Hospital, Oslo, Norway

Ø. Molberg

Department of Rheumatology,

Oslo University Hospital-Rikshospitalet, Oslo, Norway over time and some patients who are initially anti-hPAD4 negative become positive later in the disease course. The anti-hPAD4 antibodies did not affect the enzymatic activity of hPAD4 when the small substrate $N$ - $\alpha$-Benzoyl-L-arginine ethyl ester was used. However, this finding may not exclude an effect of these autoantibodies on citrullination of protein substrates in RA.

Keywords Rheumatoid arthritis - Peptidylarginine deiminase $4 \cdot$ Citrulline $\cdot$ Autoantibodies

\section{Introduction}

RA is a common, complex autoimmune disorder characterized by a chronic and destructive inflammation localized in the synovial lining of diarthrodial joints [1]. Accumulated evidence suggests that the inflammatory response in the rheumatoid joints is driven by antigen-specific $\mathrm{T}$ cells and $\mathrm{B}$ cells. The disease-causing antigens are not known, but it appears that disease-specific B cells produce antibodies specific to citrullinated proteins [1,2]. These anticitrullinated protein antibodies (ACPA) represent diseasespecific markers used for the diagnosis of RA, which can appear several years before the onset of the disease and whose presence is associated with a more severe disease course $[3,4]$. Protein-bound arginine residues are deiminated to citrulline by the $\mathrm{Ca}^{2+}$-dependent peptidylarginine deiminase family, of which the human isoform 4 (hPAD4) is a target of autoantibodies in RA patients [5-9]. We have recently shown in a large RA cohort that the presence of anti-hPAD4 autoantibodies at baseline is associated with radiographic damage after 10 years [6]. It is not known why serum anti-hPAD4 antibodies are associated with a more aggressive disease course. 
In the present work, we have addressed two key issues related to the anti-hPAD4 immune response in RA. We have investigated whether the level of serum anti-hPAD4 $\mathrm{IgG}$ is stable over a period of 10 years and tested the possibility that the antibodies could contribute to the formation of citrullinated epitopes by affecting the activity of the enzyme.

\section{Materials and methods}

Chemicals

$N$ - $\alpha$-Benzoyl-L-arginine ethyl ester (BAEE), $\beta$-NADH, glutathione, $\alpha$-ketoglutaric acid, isopropyl $\beta$-D-thiogalactopyranoside (IPTG), bovine liver glutamate dehydrogenase (GDH), and 3-[N-morpholino] propane sulfonic acid (MOPS) were from Sigma-Aldrich (St-Louis, USA). Glutathione-Sepharose 4B, Pre-scission protease, and Protein $\mathrm{G}_{\text {Sepharose }}{ }^{\mathrm{TM}} 4$ Fast Flow were from GE Healthcare BioSciences AB (Uppsala, Sweden). BCA reagents were from Pierce (Rockford, USA).

\section{Patients and sera}

Serum samples from baseline and after 10 years were available from 128 patients in the previously described Norwegian EURIDISS cohort [6]. At baseline, these patients had a disease duration of $2.5( \pm 1.2)$ years. The control group $(n=120)$ consisted of healthy individuals selected from the population register after matching for age, sex, and residential area with patients in the Oslo RA register.

hPAD4 and the anti-hPAD4 antibody assay

The full-length hPAD4 cDNA was provided by Dr. Akihito (Tokyo Metropolitan Institute of Gerontology, Japan), expressed as a fusion protein with glutathione S-transferase (GST) and purified as previously described [6, 10]. For an aliquot of hPAD4, GST was cleaved off by Pre-scission protease. Enzymatic activities were tested with BAEE and proteins (fibrinogen, ovalbumin, catalase) as substrates, using a colorimetric assay [11] and the Anti-Citrulline (modified) Detection Kit (Millipore/Temecula, CA/USA), respectively. Serum anti-hPAD4 IgG antibodies were detected by our previously described hPAD4-specific immunoassay [6].

\section{IgG purification}

Five serum samples exhibiting high levels of anti-hPAD4 IgG and two sera negative for anti-hPAD4 IgG were selected from the Oslo RA registry cohort [6]. Three controls were selected from the healthy control group. Total IgG was purified using Sepharose beads conjugated with protein $\mathrm{G}$ according to the manufacturer's instructions. $\mathrm{IgG}$ was eluted with $5 \times 100 \mu \mathrm{l} 0.1 \mathrm{M}$ glycine/ $\mathrm{HCl} \mathrm{pH} 2.5$ and collected in the tubes containing $8 \mu \mathrm{l} 1 \mathrm{M}$ Tris/ $\mathrm{HCl} \mathrm{pH9.0}$ to neutralize the $\mathrm{pH}$. Purified $\mathrm{IgG}$ was dialyzed against $100 \mathrm{mM}$ MOPS $\mathrm{pH} 7.4$, and protein concentration was determined by the method of Bradford using a BCA kit and human immunoglobulins as a standard (Octapharma A.S., Norway). Purity was confirmed by SDS-PAGE.

Depletion of anti-hPAD4 antibodies from total IgG

Purified total $\mathrm{IgG}$ was dialyzed against $100 \mathrm{mM}$ MOPS $\mathrm{pH}$ 7.4/1.5 $\mathrm{mM} \mathrm{Ca}^{2+}$. In order to deplete anti-hPAD4 IgG, the dialyzed samples were passed through an affinity column consisting of purified GST-hPAD4 bound to glutathioneSepharose 4B. Two mock depletion controls were included: a fraction of the total IgG was passed through a glutathione-Sepharose 4B column and the MOPS/ $/ \mathrm{Ca}^{2+}$ buffer was passed through a GST-hPAD4-glutathione-Sepharose 4B column. Depletion efficiency was verified by the hPAD4-specific immunoassay.

\section{Kinetic assay}

The ammonium-release assay has been described previously [10]. Briefly, the reaction mixtures (final volume of $60 \mu \mathrm{l}$ ) contained $100 \mathrm{mM}$ MOPS $\mathrm{pH}$ 7.4, $1 \mathrm{mM} \beta$-NADH, $10 \mathrm{mM} \alpha$-ketoglutaric acid, $3.95 \mathrm{U} \mathrm{GDH}, 1.5 \mathrm{mM} \mathrm{Ca}^{2+}$, $1 \mu \mathrm{g}$ purified hPAD4 $(0.18 \mathrm{U})$, and different amounts of the substrate BAEE $(0-10 \mathrm{mM})$. GDH, $\beta$-NADH, and $\alpha$-ketoglutarate solutions were freshly prepared, and reactions were carried out in Maxisorp 96-well plates (Nunc, Rochester, USA). Mixtures were pre-incubated for $10 \mathrm{~min}$ at $37^{\circ} \mathrm{C}$ in the presence of $110 \mu \mathrm{g} / \mathrm{ml}$ purified $\mathrm{IgG}$, and reactions were started by the addition of BAEE. Decrease in absorbance at $340 \mathrm{~nm}$ was measured in a 1420 VIC$\mathrm{TOR}^{3 \mathrm{TM}}$ multilabel counter (Perkin-Elmer, Wallac, Finland). $\beta$-NADH concentration was determined based on a $\beta$-NADH standard curve $(0-1 \mathrm{mM})$. Initial velocities obtained from these experiments were plotted over the substrate concentration (Michaelis-Menten plot). Experiments without BAEE were carried out to control for citrullination of proteins present in the assay (IgG, GDH, hPAD4), which would alter the kinetics (data not shown).

Statistical analyses

Analyses were performed using GraphPad InStat version 3.06 for Windows, GraphPad Software (San Diego, USA). 


\section{Results}

Anti-hPAD4 IgG in RA sera at baseline and after 10 years

To ensure a low inter-assay variability of our assay, the 128 baseline RA sera were retested and the measured levels of anti-hPAD4 IgG antibodies were compared with our previously published data [6]. Reproducibility of data was confirmed by a linear correlation test ( $r=0.96)$ (Fig. 1). In the majority of the 128 RA patients, we observed that the baseline levels of anti-hPAD4 IgG antibodies remained stable over 10 years (Fig. 2a). Three sera that had low levels of anti-hPAD4 IgG at baseline had become negative at 10 years. Interestingly, seven sera, which were antihPAD4 negative at baseline, had become positive after 10 years (Fig. 2b). Among these, four sera were anti-CCP2 positive at baseline and after 10 years. Radiographic joint damage data after 10 years were available for six of these seven patients and showed that five out of these six had severe erosive disease with a total van der Heidje modified Sharp score above 30 (data not shown). As shown in our previous study, anti-hPAD4 IgG levels correlate with the levels of anti-CCP antibodies and a higher longitudinal radiographic damage score [6].

\section{Influence of anti-hPAD4 antibodies on hPAD4 catalytic} activity

The range of anti-hPAD4 IgG concentrations used in the kinetic assay was chosen according to the method employed by Kiraly et al. [12]. First, purified IgG was titrated in the hPAD4-specific immunoassay in order to determine the $\operatorname{IgG}$ concentration that gave maximal

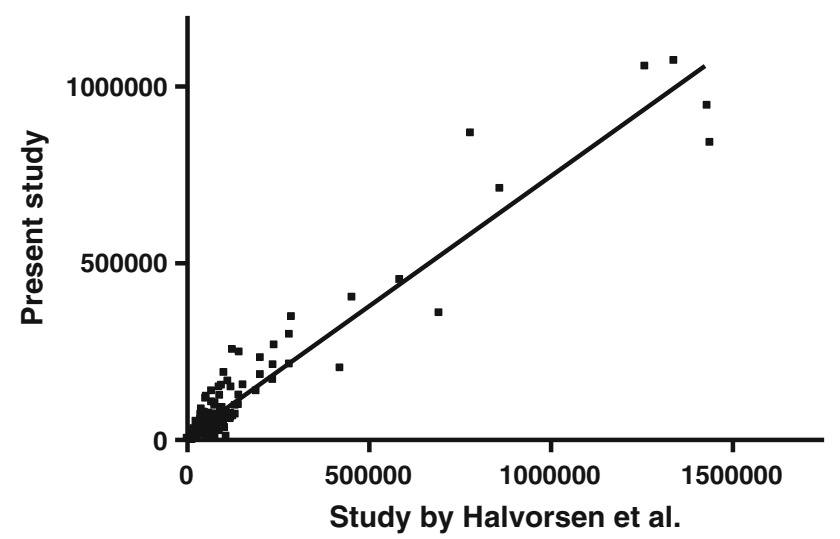

Fig. 1 Inter-assay variability of the anti-hPAD4 immunoassay. The level of anti-hPAD4 IgG (expressed as emission signals) was assessed at baseline in sera from 128 patients in the EURIDISS RA cohort, and the results were compared with our previously published data on the same sera. The correlation analysis $(r=0.96)$ confirmed that the results were reproducible
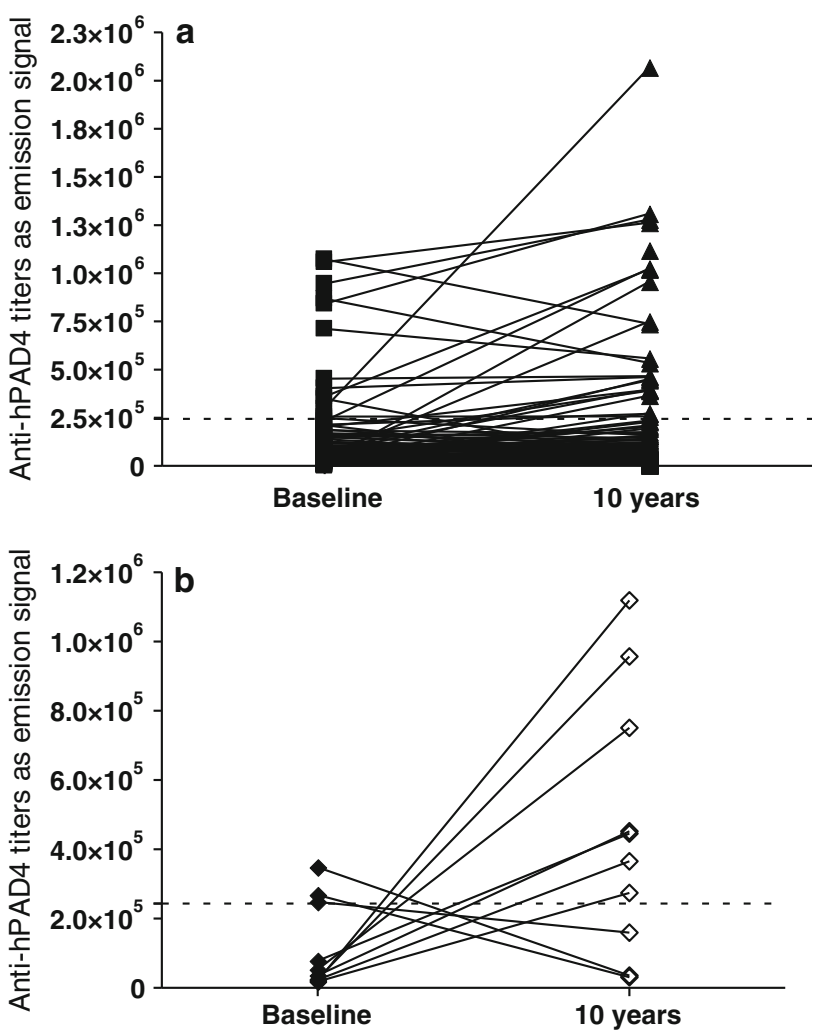

Fig. 2 a Assessment of serum anti-hPAD4 IgG levels in RA sera at baseline and after 10 years. The sera were diluted 1:2,000 before incubation, measurements were taken in duplicates, and the antihPAD4 IgG levels are expressed as the mean emission signal after subtraction of the background signal. b Assessment of serum antihPAD4 IgG levels in RA sera at baseline and after 10 years. Depicted are the three patients who were anti-hPAD4 positive at baseline and negative after 10 years, and the seven patients who were anti-hPAD4 negative at baseline and positive after 10 years. The sera were diluted 1:2,000 before incubation, measurements were taken in duplicates, and the anti-hPAD4 IgG activity levels are expressed as the mean emission signal after subtraction of the background signal

absorbance. To ensure sufficient concentrations of antihPAD4-specific antibodies in the hPAD4 kinetic assay, we applied a concentration of purified $\operatorname{IgG}$ that was 30 -fold higher than the value determined by these titration experiments (i.e., $110 \mu \mathrm{g} / \mathrm{ml}$ ). In additional control experiments, concentrations as high as $400 \mu \mathrm{g} / \mathrm{ml}$ of purified $\mathrm{IgG}$ were tested.

The purified serum IgG fractions were then subjected to depletion of anti-hPAD4 antibodies. As evaluated by the hPAD4-specific immunoassay, this procedure resulted in quantitative removal of anti-hPAD4 IgG (Fig. 3a). The effects of the purified serum IgG fractions and of the antihPAD4-depleted IgG fractions on hPAD4 activity were assessed by the ammonium-release assay. The $k_{c a t}$ and $K_{m}$ values for hPAD4-catalyzed deimination of BAEE were determined in the presence of total $\operatorname{IgG}$ fractions or $\mathrm{IgG}$ fractions depleted from anti-hPAD4. To ensure that the 
depletion procedure itself did not affect the measured kinetic parameters, we also performed the assay in the presence of mock-depleted IgG. Interestingly, similar $k_{\text {cat }}$ / $K_{m}$ values were found under all these conditions (Fig. 3b and Table 1), suggesting that anti-hPAD4 antibodies do not interfere with enzymatic activity.

\section{Discussion}

The role of hPAD4 in RA has been extensively studied during the last years. Several studies found an association

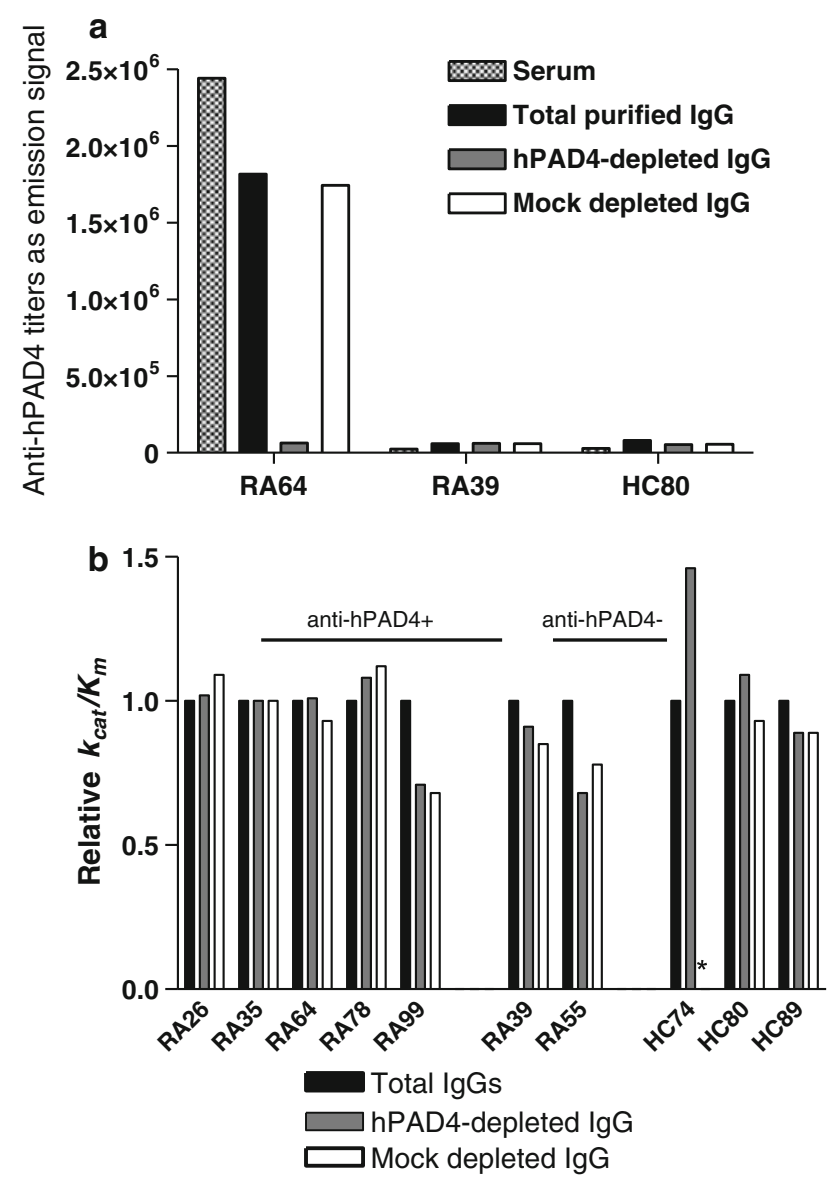

Fig. 3 a Detection of anti-hPAD4 antibodies in serum, in total IgG purified from the same serum, in serum depleted from anti-hPAD4 antibodies, and in mock depletion controls. The hPAD4-specific fluorometric immunoassay was used, and results from three individual sera are shown; patients RA64 (anti-hPAD4 positive) and RA39 (antihPAD4 negative) and the healthy control HC80. The sera and the IgG fractions were diluted 1:2,000 before incubation. b Influence of antihPAD4 antibodies on hPAD4-mediated deimination of BAEE. Shown are the relative $k_{\text {cat }} / K_{m}$ values for the total IgG fraction, IgG depleted from anti-hPAD4 antibodies, and the mock-depleted total IgG. Data are shown for five anti-hPAD4-positive and two anti-hPAD4-negative RA patients and for three healthy controls. The $k_{c a t} / K_{m}$ value for each total IgG fraction was normalized to one. All the experimental $k_{c a t} / K_{m}$ values are provided in Table 1 . (*) $k_{c a t} / K_{m}$ value was not determined between polymorphisms in the hPAD4 gene and disease risk [8, 13-15]. Furthermore, antibodies directed against hPAD4 have been identified and shown to be associated with anti-CCP positivity, progressive disease, and also persistent radiographic damage in RA patients receiving anti-TNF- $\alpha$ therapy $[6,8]$.

We have previously shown anti-hPAD4 data at baseline from 237 patients in the EURIDISS RA cohort [6]. Now, we present the 10-year follow-up data on 128 patients from this EURIDISS cohort which show that individual RA patients have remarkably stable titers of anti-PAD4 antibodies. Only seven RA patients who were initially antihPAD4 negative had become positive at follow-up. It is interesting, however, to note that disease progressed in five of six of these patients from whom we had radiographic joint damage data.

Serum anti-hPAD4 IgG, similarly to the anti-CCP antibodies [16], appears early in the disease course and remains present in the serum over time. Whether they contribute to the chronicity of the disease is unclear. We hypothesized that the antibodies could influence the activity of the enzyme in vivo and thereby modulate the protein citrullination process. For other human diseases, such as Wegener's granulomatosis and autoimmune thyroiditis, it has been suggested that the binding of specific antibodies to enzymes affects the activity of the enzyme $[17,18]$. However, under our experimental conditions, we did not find that the anti-hPAD4 IgG antibodies had an effect on hPAD4-mediated deimination of a model substrate. This result does not exclude that anti-hPAD4 antibodies may have effects on the enzyme in vivo. It is, for instance, possible that the binding of the anti-hPAD4 antibodies may stabilize the enzyme and protect it from degradation. An alternative explanation might be that PAD4-containing immune complexes have pro-inflammatory properties that contribute to the more pronounced joint erosion observed in the anti-hPAD4-positive patients.

In contrast to our results, Auger et al. [19] recently published that anti-hPAD4 antibodies inhibit hPAD4mediated citrullination of fibrinogen. It should be noted that they used an approach different from ours to address the effect of those antibodies on hPAD4 activity. Whereas Auger et al. used a protein substrate of hPAD4, our experiments were carried out with the small arginine-derivative BAEE. As anti-PAD4 autoantibodies may not only directly influence the enzymatic activity but could also interfere with substrate binding, the small BAEE molecule may still be able to enter the active site whereas binding of the large substrate fibrinogen may be sterically blocked. Notably, antibody binding to the C-terminal part of PAD4, which contains the active site [20], has been demonstrated [8, 19]. Secondly, Auger 
Table 1 Parameters $k_{c a t}$ and $K_{m}$ as measured in the kinetic assay

\begin{tabular}{|c|c|c|c|c|c|c|c|c|c|}
\hline \multirow{2}{*}{$\begin{array}{l}\text { RA sera } \\
\text { (anti-hPAD4 emission } \\
\left.\text { signals }\left[\times 10^{6}\right]\right)\end{array}$} & \multicolumn{3}{|c|}{ Purified total $\operatorname{IgG}$} & \multicolumn{3}{|c|}{ Purified total IgG depleted from anti-hPAD4 antibodies } & \multicolumn{3}{|c|}{ Control depletion } \\
\hline & $\begin{array}{l}K_{m} \\
{[\mathrm{mM}]}\end{array}$ & $\begin{array}{l}k_{\text {cat }} \\
{\left[\mathrm{s}^{-1}\right]}\end{array}$ & $\begin{array}{l}k_{c a t} / K_{m} \\
{\left[\mathrm{~s}^{-1} \mathrm{M}^{-1}\right]}\end{array}$ & $\begin{array}{l}K_{m} \\
{[\mathrm{mM}]}\end{array}$ & $\begin{array}{l}k_{c a t} \\
{\left[\mathrm{~s}^{-1}\right]}\end{array}$ & $\begin{array}{l}k_{\text {cat }} / K_{m} \\
{\left[\mathrm{~s}^{-1} \mathrm{M}^{-1}\right]}\end{array}$ & $\begin{array}{l}K_{m} \\
{[\mathrm{mM}]}\end{array}$ & $\begin{array}{l}k_{c a t} \\
{\left[\mathrm{~s}^{-1}\right]}\end{array}$ & $\begin{array}{l}k_{\text {cat }} / K_{m} \\
{\left[\mathrm{~s}^{-1} \mathrm{M}^{-1}\right]}\end{array}$ \\
\hline \multicolumn{10}{|l|}{ Anti-PAD4-positive sera } \\
\hline RA26 (1.59) & 1.35 & 5.26 & 3,890 & 0.85 & 3.38 & 3,970 & 0.8 & 3.38 & 4,225 \\
\hline RA35 (1.43) & 1.60 & 3.75 & 2,340 & 1.60 & 3.75 & 2,340 & 1.60 & 3.75 & 2,340 \\
\hline RA64 (1.59) & 1.40 & 5.20 & 3,710 & 1.50 & 5.60 & 3,730 & 1.50 & 5.20 & 3460 \\
\hline RA78 (1.02) & 1.40 & 5.26 & 3,750 & 1.30 & 5.26 & 4,040 & 1.25 & 5.26 & 4,200 \\
\hline RA99 (1.14) & 1.00 & 3.38 & 3,380 & 1.25 & 3.00 & 2,400 & 1.30 & 3.00 & 2,300 \\
\hline \multicolumn{10}{|l|}{ Anti-PAD4-negative sera } \\
\hline RA39 (0.023) & 1.20 & 5.51 & 4,591 & 1.49 & 6.19 & 4,154 & 1.25 & 4.87 & 3,896 \\
\hline RA55 (0.021) & 1.50 & 4.50 & 3,000 & 1.75 & 3.60 & 2,050 & 1.45 & 3.38 & 2,330 \\
\hline \multicolumn{10}{|l|}{ Healthy control sera } \\
\hline HC74 (0.032) & 1.50 & 2.25 & 1,500 & 1.20 & 2.63 & 2,192 & nd & nd & nd \\
\hline HC80 (0.016) & 0.75 & 2.40 & 3,200 & 0.75 & 2.63 & 3,506 & 0.75 & 2.25 & 3,000 \\
\hline HC89 (0.046) & 1.20 & 3.38 & 2,810 & 1.20 & 3.00 & 2,500 & 1.20 & 3.00 & 2,500 \\
\hline $\begin{array}{l}\text { Buffer control } \\
(0.005)\end{array}$ & & & & & & & 0.90 & 2.63 & 2,900 \\
\hline
\end{tabular}

Recombinant hPAD4 was incubated with purified IgG or with MOPS buffer. The values shown are from one representative experiment. Anti-hPAD4 emission signals were obtained in the hPAD4-specific fluorometric immunoassay

et al. purified hPAD4-specific antibodies using hPAD4 adsorbed to the surface of ELISA plates, whereas we used sera depleted from hPAD4 antibodies by capturing them on a GST-PAD4 affinity matrix. It might therefore be that the antibodies explored in both studies fall into two populations that are not exactly identical. For example, absorption of PAD4 to the plate may induce changes in the enzyme's tertiary structure [21] that is likely to affect the binding of antibodies directed against conformational epitopes. Although a direct comparison of the results obtained from both studies appears difficult, they can be considered as supplementary data describing the influence of anti-PAD4 autoantibodies on the enzymatic activity.

In conclusion, we confirm that anti-hPAD4 antibodies, which are a useful marker of disease severity in RA at baseline, do not disappear over time. However, our study does not show an effect of anti-hPAD4 IgG on the activity of the hPAD4 enzyme when a small substrate is used. Further investigations into the mechanisms that link antihPAD4 antibodies to erosive disease and resistance to anti$\mathrm{TNF} \alpha$ treatment are therefore required in the future.

Acknowledgments We thank Keith Thompson for his help with the statistical analysis. This work was supported by grants from the Research Council of Norway and Oslo University HospitalRikshospitalet.

Conflict of Interest We declare no competing interests.
Open Access This article is distributed under the terms of the Creative Commons Attribution Noncommercial License which permits any noncommercial use, distribution, and reproduction in any medium, provided the original author(s) and source are credited.

\section{References}

1. Molberg O, Sollid LM (2006) A gut feeling for joint inflammation-using coeliac disease to understand rheumatoid arthritis. Trends Immunol 27:188-194

2. Klareskog L, Ronnelid J, Lundberg K, Padyukov L, Alfredsson L (2008) Immunity to citrullinated proteins in rheumatoid arthritis. Annu Rev Immunol 26:651-675

3. Zendman AJ, van Venrooij WJ, Pruijn GJ (2006) Use and significance of anti-CCP autoantibodies in rheumatoid arthritis. Rheumatology (Oxford) 45:20-25

4. Nikolaisen C, Rekvig OP, Nossent HC (2007) Diagnostic impact of contemporary biomarker assays for rheumatoid arthritis. Scand J Rheumatol 36:97-100

5. Auger I, Balandraud N, Rak J, Lambert N, Martin M, Roudier J (2009) New autoantigens in rheumatoid arthritis (RA): screening 8268 protein arrays with sera from patients with RA. Ann Rheum Dis 68:591-594

6. Halvorsen EH, Pollmann S, Gilboe IM et al (2008) Serum IgG antibodies to peptidylarginine deiminase 4 in rheumatoid arthritis and associations with disease severity. Ann Rheum Dis 67:414-417

7. Halvorsen EH, Haavardsholm EA, Pollmann S et al (2009) Serum IgG antibodies to peptidylarginine deiminase 4 predict radiographic progression in patients with rheumatoid arthritis treated with tumour necrosis factor-alpha blocking agents. Ann Rheum Dis 68:249-252 
8. Harris ML, Darrah E, Lam GK et al (2008) Association of autoimmunity to peptidyl arginine deiminase type 4 with genotype and disease severity in rheumatoid arthritis. Arthritis Rheum 58:1958-1967

9. Takizawa Y, Sawada T, Suzuki A, Yamada R, Inoue T, Yamamoto K (2005) Peptidylarginine deiminase 4 (PADI4) identified as a conformation-dependent autoantigen in rheumatoid arthritis. Scand J Rheumatol 34:212-215

10. Stensland ME, Pollmann S, Molberg O, Sollid LM, Fleckenstein B (2008) Primary Sequence, together with other factors, influence peptide deimination by peptidylarginine deiminase-4. Biol Chem 390:99-107

11. Nakashima K, Hagiwara T, Ishigami A et al (1999) Molecular characterization of peptidylarginine deiminase in HL-60 cells induced by retinoic acid and 1alpha, 25-dihydroxyvitamin $\mathrm{D}(3)$. J Biol Chem 274:27786-27792

12. Kiraly R, Vecsei Z, Demenyi T, Korponay-Szabo IR, Fesus L (2006) Coeliac autoantibodies can enhance transamidating and inhibit GTPase activity of tissue transglutaminase: dependence on reaction environment and enzyme fitness. J Autoimmun 26:278-287

13. Hoppe B, Haupl T, Gruber R et al (2006) Detailed analysis of the variability of peptidylarginine deiminase type 4 in German patients with rheumatoid arthritis: a case-control study. Arthritis Res Ther 8:R34

14. Ikari K, Kuwahara M, Nakamura T et al (2005) Association between PADI4 and rheumatoid arthritis: a replication study. Arthritis Rheum 52:3054-3057
15. Plenge RM, Padyukov L, Remmers EF et al (2005) Replication of putative candidate-gene associations with rheumatoid arthritis in \&gt;4, 000 samples from North America and Sweden: association of susceptibility with PTPN22, CTLA4, and PADI4. Am J Hum Genet 77:1044-1060

16. Rantapaa-Dahlqvist S, de Jong BA, Berglin E et al (2003) Antibodies against cyclic citrullinated peptide and IgA rheumatoid factor predict the development of rheumatoid arthritis. Arthritis Rheum 48:2741-2749

17. Daouk GH, Palsson R, Arnaout MA (1995) Inhibition of proteinase 3 by ANCA and its correlation with disease activity in Wegener's granulomatosis. Kidney Int 47:1528-1536

18. Kohno Y, Yamaguchi F, Saito K, Niimi H, Nishikawa T, Hosoya $\mathrm{T}$ (1991) Anti-thyroid peroxidase antibodies in sera from healthy subjects and from patients with chronic thyroiditis: differences in the ability to inhibit thyroid peroxidase activities. Clin Exp Immunol 85:459-463

19. Auger I, Martin M, Balandraud N, Roudier J (2010) Rheumatoid arthritis-specific autoantibodies to peptidyl arginine deiminase type 4 inhibit citrullination of fibrinogen. Arthritis Rheum 62:126-131

20. Arita K, Hashimoto H, Shimizu T, Nakashima K, Yamada M, Sato M (2004) Structural basis for $\mathrm{Ca}(2+)$-induced activation of human PAD4. Nat Struct Mol Biol 11:777-783

21. Engel MF, van Mierlo CP, Visser AJ (2002) Kinetic and structural characterization of adsorption-induced unfolding of bovine alpha -lactalbumin. J Biol Chem 277:10922-10930 